
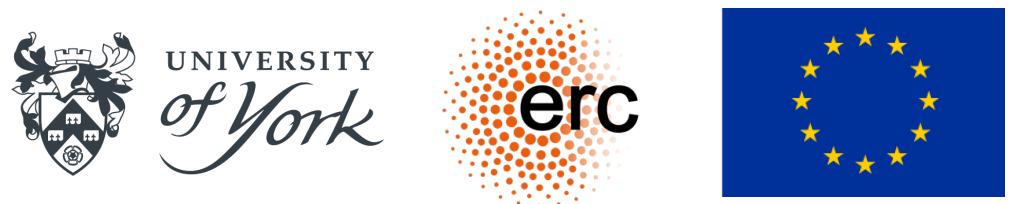

Teacher Selection Project Working Paper

08.08.20

\title{
Attracting Prospective STEM Teachers Using Realistic Job Previews: A Mixed Methods Study
}

Robert M. Klassen, Helen Granger, and Lisa Bardach

University of York

This Working Paper reports in-progress work that is not yet peer reviewed. The purpose of the Working Paper is to stimulate discussion and to contribute to the advancement of knowledge. Please check our project website for news of recent publications. This work is supported by the European Research Council (grant \#647234 SELECTION) 


\title{
Attracting Prospective STEM Teachers Using Realistic Job Previews: A Mixed Methods Study
}

\begin{abstract}
Attracting the best possible applicants into initial teacher education (ITE) programmes has been a long-standing challenge in the UK and internationally, and the situation is especially urgent in STEMrelated subjects. The purpose of this article is to report the development and implementation of an online teacher attraction intervention—realistic job previews (RJPs) — based on person-environment (and person-vocation) fit theory. Study 1 reports the online administration of an RJP consisting of four animated classroom scenarios requiring participant responses, followed by experienced teacher feedback and a tailored fit message to 111 university students in STEM-related fields. Results showed a significant relationship between RJP performance and interest in a teaching career, even after controlling for prior career intentions (i.e., intentions to pursue a career in teaching). Study 2 reports findings from individual interviews with 14 university students studying STEM-related subjects on the factors contributing to career-decision making, especially regarding teaching as a career. The 16 codes were distilled into three themes: the role of personal reflection, critical influences on career decisions, and patterns of change. We conclude with suggestions for implementation of RJPs as a supplement to current attraction and recruitment approaches.
\end{abstract}

\section{Introduction}

Recruiting high quality teachers is an international challenge, with shortages especially acute in STEM-related subjects (science, technology, engineering, and mathematics; See \& Gorard, 2019). Teacher attraction strategies typically involve an appeal to one of two motivations to enter the profession: (a) they emphasise the personal utility of pursuing a teaching career by offering grants and bursaries for training, higher salaries, improved working conditions, and/or (b) they emphasise the social utility of teaching by highlighting how a teaching career can make a social contribution in terms of improving the lives of children and advancing positive social change (e.g., the UK Department for Education's [DfE] Every Lesson Shapes a Life campaign). However, attraction and recruitment strategies based on 'seduction' approaches have a downside: although they may attract applicants in the short term, they may lead to unrealistically high expectations, lower job satisfaction, and increases in quitting intentions (Baur, Buckley, Bagdasarov, \& Dharmasiri, 2014). One generally unexplored avenue to building teacher recruitment strategies is using a 'person-environment fit' approach, in which prospective teachers are identified and recruited based on the compatibility between individual characteristics and the work environment. In this article, we present a mixedmethods study demonstrating how a proof-of-concept person-environment fit approach using 'realistic job previews' (RJPs) could provide an additional method used to recruit teachers in hard-to-staff fields.

\section{The Teacher Recruitment Landscape}


Many countries are currently facing significant teacher shortages. In 2016 UNESCO predicted that there was a global shortfall of nearly 70 million teachers, with acute shortages for both primary and secondary teachers. In the UK, the shortage of teachers in STEM-related fields is especially acute, with maths and science teachers consistently under-recruited since at least 20112012, with growing shortfalls predicted (Foster, 2019). Attempts to remedy the shortages are usually addressed through personal utility interventions (e.g., through offering financial incentives) or social utility interventions (e.g., through highlighting the social impact achieved through teaching).

Although these personal and social attractants may be successful for initial recruitment, their impact tends to dissipate or disappear when the incentive is removed (See, Morris, Gorard, \& El Soufi, 2020). The current COVID-19 crisis and impending economic crisis may temporarily increase the number of ITE applicants, as recent graduates find it more difficult to find vacancies in businesses that may reduce their intake of new employees due to economic constriction. Evidence from the 2008 financial crisis showed that occupations such as teaching are more 'recession proof' than many other fields, with improvements seen in teacher recruitment, although the effects tend to fade over time (Fullard, 2020). However, a general theme in teacher recruitment research is that external factors that initially increase the flow of graduates into teaching (financial incentives or global economic uncertainty) may not make a lasting impact if the fit between applicant and job is not adequately considered.

\section{Theories Relevant to Attraction and Recruitment}

Person-environment fit. Person-environment fit is one of the major theories in psychology, and describes how people who are well matched to an environment, for example their workplace, demonstrate positive psychological adjustment and performance (Barrick \& Parks-Leduc, 2019). In education settings, recent studies have shown that teachers who believed their abilities and attitudes closely matched the demands of teaching were less likely to leave the profession (De Cooman et al., 2009; Player, Youngs, Perrone, \& Grogan, 2017). Most of the work on PE fit has been conducted in organisational psychology, where fit has been studied at various levels, including fit with the organisation (person-organisation fit), the particular job (person-job fit), and with choice of vocation (person-vocation fit), which is the focus of this article. There is considerable overlap between the levels of person-environment fit constructs, but they are conceptually different: an employee can fit well with a general occupation (high person-vocation fit) but finds herself ill-suited to a particular organisation (low person-organisation fit). Vogel and Feldman (2009) found a strong association between person-vocation fit and workplace attitudes (job satisfaction, commitment, perceptions of career success, and retention), and workplace performance. A large-scale meta-analysis that explored predictors of applicant attraction (Uggerslev, Fassina, \& Kraichy, 2012) showed that perceived fit was the strongest relative and unique variance predictor of applicant attraction across multiple stages of the recruitment process, with a large effect size $(R=.55)$, suggesting that perceived fit plays a key 
role in career decision-making. In this study, the focus is on the fit between the person and teaching (person-vocation fit).

FIT-Choice theory. Building on person-environment fit and expectancy-value theories, Watt and Richardson's FIT-Choice motivation theory provides another framework for understanding why people enter the teaching profession (e.g., Watt \& Richardson, 2016), with application to teacher recruitment. The FIT-Choice framework defines expectancies as a form of competence and selfefficacy beliefs (How well could I do in this profession?) which interact with interest and beliefs about the utility or value of a career choice. Self-efficacy is enhanced (Bandura, 1997) when positive verbal messages about capabilities are provided (such as through fit messages), and through observation of successful models (such as through feedback from experienced professionals).

Utility values can be broken down into personal utility (How do I benefit from this career choice?) and social utility (How could this career help me make a social contribution?). When making career decisions, individuals perform an implicit calculation based on these three factors: perceived competence, personal utility, and the social utility of their potential career choice. However, in education settings, the vast majority of teacher recruitment efforts have been based on promoting the personal utility of teaching (through financial incentives, workload reductions) and the social utility of teaching (e.g., Every lesson shapes a life, DfE 2020), often at considerable cost to taxpayers (e.g., Carr, 2020). Broad messages to promote personal and social utility of teaching are possibly effective in attracting applicants, but less effective in retaining teachers in the long term (e.g., See et al., 2020). Little attention in education has been paid to developing recruitment strategies that use a person-environment fit framework, where fit messages are provided to candidates to help them evaluate the match between their personal characteristics and those required for success in teaching.

Feedback and fit messages. From a social cognitive theory perspective, being in the receipt of feedback and fit messages delivered by experts can form two sources of self-efficacy: verbal persuasion and vicarious experience (Bandura, 1997). Uggerslev et al. (2012) concluded that recruitment processes could be improved with the inclusion of fit messages to applicants before and during the recruitment process. However, determining fit is not straightforward: fit can be viewed from the perspective of the applicant and from the organisation. For an organisation, person-vocation fit is the focus of the selection process, and is evaluated through screening and interviewing to assess cognitive and non-cognitive attributes and relevant background experiences (e.g., Author et al., 2020a). From the applicant's perspective, their own fit is determined through a self-assessment of personal characteristics (e.g., cognitive and non-cognitive attributes) measured against the perception of the attributes needed for success in a particular vocation. When considering a teaching career, this self-assessment of fit interacts with perceptions of personal and social utility of the profession, and by the messages delivered by the organisation through recruitment messaging, such as through advertisements in social and traditional media. 
When receiving feedback and fit messages, a candidate will ask herself three questions, the first two corresponding to personal utility (personal benefits) and social utility (social contribution), and the third about person-vocation fit: Do my knowledge, skills, and attributes fit with those demanded by the profession? Each potential candidate will weigh these three factors using a different calculus, but each of these factors play a part in making career decisions.

Although recruitment messages about the personal and social utility are an important part of an overall recruitment strategy, a higher degree of specificity in recruitment messages is preferable, because specific fit messages produce more favourable applicant perceptions and reactions (Roberson, Collins, \& Oreg, 2005). Meaningful feedback on fit demands some form of interaction between an organisation and potential candidates as part of a long-term recruitment process, something that can be expensive and time consuming in practice. In the UK, the DfE references the Discover Teaching programme in its recent recruitment strategy (DfE, 2019), providing opportunity for teaching internships, school taster days, and a virtual reality classroom experience. However, these programmes are difficult and expensive to scale up to reach the large numbers of potential candidates needed to maintain the teaching pipeline. In other fields, a scalable recruitment approach using realistic job previews provides a way of providing potential applicants with valuable data regarding their fit with the profession.

\section{Realistic Job Previews (RJPs)}

Realistic job previews (RJPs) are a recruitment method where potential applicants are presented with a realistic view of situations they can expect from a job. Research on RJPs has been conducted for over a half-century, with results showing that RJPs delivered before training or employment can promote early integration into a new field, leading to better retention rates and job success (Baur et al., 2014). The integration of RJPs into the recruitment process affords three benefits: (a) they communicate an honest and believable portrayal of a job, leading to higher levels of trust for potential applicants (the 'air of honesty' hypothesis), (b) they lower initial expectations so that new trainees are prepared for the inevitable ups and downs encountered in the job (the 'met expectations' hypothesis), and (c) they lead to appropriate self-selection where applicants will self-select out if the job is not a good fit (the 'self-selection' hypothesis). Combining RJPs with explicit person-vocation fit feedback builds on the self-selection hypothesis: the combination of RJP + feedback attracts potential candidates who receive positive fit feedback, and deters those who receive a message that they may not be well-suited to a particular vocation (Earnest, Allen, \& Landis, 2011; Roberson et al., 2005).

RJPs can be delivered through a range of materials (written or video presentations) that provide applicants with balanced (positive and negative) information about the potential job. The accuracy and specificity of recruitment messages is associated with enhanced person-vocation fit, meaning that applicants for training or employment can make more informed decisions about entering training or employment, resulting in better perceived fit and increased intentions to apply (Roberson 
et al., 2005). Feedback messages related to person-vocation fit can form a component of the RJP, similar to the approach taken in situational judgment tests (SJTs), a scenario-based method frequently used for selection in medical education, and increasingly, in teacher education (e.g., Author et al., 2020b). In both applications of these two scenario-based methods, applicants are (a) exposed to a realistic scenario, (b) answer questions about appropriate courses of action, and (c) are provided with a fit message based on the accuracy of their responses (as compared to subject matter experts). For teacher recruitment, the advantage of delivering fit messages to potential candidates using an RJP approach is that applicants who may not have considered teaching as a career can be provided with authentic, detailed, and believable portrayals of the workplace environment and receive an indication of how their decision-making fits with professionals in the field.

\section{Current Study}

In this article, we explore how an RJP intervention with fit messages grounded in social cognitive and PE fit theories might be used to attract prospective teachers to the profession. In Study 1 , we measure the effects of an RJP intervention on 111 university students' interest in teaching as a career, self-efficacy for teaching, the perceived match between personal attributes and those attributes required to be a teacher. In Study 2, we interviewed 14 university students from STEM-related disciplines (economics, physics, mathematics, and engineering) to gain an understanding of the factors that influence their decisions to consider teaching as a career. The primary research questions were:

1. Is there an association between person-vocation fit as measured in a brief RJP intervention and university students' teaching self-efficacy, interest in teaching as a career, and perceived match between personal attributes and those attributes necessary for teaching? We hypothesized that a stronger fit would positively predict teaching self-efficacy, interest in teaching as a career, and perceived match between personal attributes and those attributes necessary for teaching.

2. What do university students in STEM-related disciplines say about the influences on their career decision-making?

\section{Study 1 Method}

\section{Participants and Procedure}

The sample for the current study was recruited via regular newsletters sent out to undergraduate students in STEM or STEM-related fields through careers advisors who had agreed to disseminate our email invitation to their students. We initially contacted departments of Biology, Chemistry, Economics (a source of maths applicants to PGCE programs), Electrical Engineering, Mathematics, and Physics, and received responses from careers advisors in Economics, Physics, Mathematics, and Electrical Engineering. A total of 118 students started the online questionnaire. Data from seven participants were deleted as they quit the survey without responding to any questions or with only responding to a few questions asking for socio-demographic characteristics. The sample 
analysed in this study thus consisted of 111 participants. The participants were on average 22.99 years old $(S D=2.62)$ and $34.2 \%$ identified as female. The participants were enrolled in the following degree programs: Economics (45.9\%), Physics (20.7\%), Mathematics (12.6\%), and Electrical Engineering (9.9\%), with the remaining participants (10.8\%) enrolled in cross-degree programs.

The online questionnaire started with questions regarding key sociodemographic characteristics (e.g., gender, age). After that, participants were asked to rate whether they planned to pursue a career in different fields (e.g., research, health profession etc.). One of these items referred to a career in teaching, and was included in order to be able to control for prior intentions to pursue a teaching career in the analyses. After that, the participants worked on the realistic job preview task (with follow-up questions) and then filled out the questionnaire (scales assessing self-efficacy, interest in exploring teaching as a career, and the match between own skills and skills required to be a teacher). Each participant who participated in the study received an Amazon shopping voucher (£6).

\section{Measures}

Realistic job previews. The RJP intervention consisted of four animated classroom scenarios delivered to participants' phone, tablet, or computer. The RJPs were initially developed for use in situational judgment tests for selection into initial teacher education programs (see Author et al., 2020b).

Figure 1 provides an example screenshot of one of the scenarios with participant options and Figure 2 provides an example of the teacher feedback. For each scenario, participants:

1. Viewed a brief classroom scenario with audio narration that presented a challenging situation

2. Rated the appropriateness of three possible responses to the dilemma posed in the scenario using a (1) Inappropriate to (4) Appropriate scale

3. Wrote a reflective rationale for their response

4. Received real-time feedback on the alignment between their own ratings and the ratings from experienced teachers

5. Were provided with a rationale from experienced teachers for appropriate responses to the dilemma

The scoring key for the RJPs had been established based upon concordance panels with subject matter experts in the field by adopting a consensus approach (see Bergman, Drasgow, Donovan, Henning, \& Juraska, 2006 for details). A panel of experienced teachers developed the initial scoring key which was then adapted based upon level of expert consensus, item difficulty, item-total correlations, and applicant (teacher education candidates) scoring patterns. The scoring was based on the scoring system described by Author et al., (2020b). Points were allocated based on the extent to which participants' responses align with the established scoring key; for example, student teachers were allocated three points if their response was in direct alignment with the scoring key, two points if their answer was one position away, one point if their answer was two positions away, and no points 
if three positions away.

After completing all scenarios, the total score (i.e., the sum of the scores of all scenarios) was shown to the participants and they received a "fit"-message: Depending on their scores, one of four messages was shown to them: (1) "Excellent fit (You think like a teacher! Your judgment matches closely with that of experienced teachers)" for those with very high scores (i.e., 29-36), (2) Very good fit (You think like a teacher! Your judgment matches quite closely with that of experienced teachers), for those with scores between 21 and 28, (3) "Quite good fit (Some experienced teachers think differently than you about these situations. But you have the capability to improve)" for participants with scores between 13 and 20, and (4) "Some areas of fit (Most experienced teachers think differently than you about these situations)" for those with 12 or less) ${ }^{1}$.

Self-efficacy. We measured self-efficacy with items adapted from the Teacher Sense of Efficacy Scale (TSES, Tschannen-Moran \& Woolfolk Hoy, 2001). Three items were used (sample item: 'I am confident that I could create a positive classroom atmosphere', $\alpha=.850$ ). The response format ranged from 1 (strongly disagree) to 7 (strongly agree).

Interest in exploring a teaching career. Three items adapted from Hackett et al.'s occupational commitment scale (Hackett, Lapierre, \& Hausdorf, 2001) were employed to assess participants' interest in exploring teaching as a career. Following the question: "Compared to how you felt before completing the activity, how much did your views change on the following items?", the participants rated the extent to which their views had changed on a with 7 response categories $(-3$ $=$ Less interested, $0=$ no change, $3=$ more interested, sample item: "I am interested in exploring teaching as a career", $\alpha=.891$ ). It should be noted that we re-coded the responses in accordance with the response format of the other scales (i.e., 1-7 instead of -3 to 3) prior to the analyses.

Attribute match. Three items adapted from Chuang et al. (Chang, Shen, \& Judge, 2015) were used to measure the perceived match between participants' own attributes and the attributes required for a teaching career (sample item: "There is a close match between my skills, knowledge, and abilities and those required for a teaching career", $\alpha=.745)$. The response format ranged from 1 (strongly disagree) to 7 (strongly agree).

Control variable. One item adapted from Hackett et al. (2001) was used to measure participants' career intentions prior to working on the scenario-based task ("After I graduate, I am interested in exploring a career as a teacher"). Participants indicated their level of agreement with the statement on a response scale ranging from 1 (strongly disagree) to 7 (strongly agree).

\section{Analysis}

Analyses were conducted with Mplus Version 8.2 using the robust maximum likelihood estimator (MLR). There was no missing data on any of the variables used in the analyses. In order to

\footnotetext{
${ }^{1}$ No participant in the present study had a score of 12 or lower.
} 
investigate whether higher scenario-scores and thus, a stronger "fit"-message predicted higher levels of self-efficacy and interest, and a higher perceived match between own skills and skills required to be a teacher, we ran a regression using scenario scores as predictor for the three outcomes (Model 1). As a next step, we included the control variable (item asking the participants to indicate if they considered exploring teaching as a career that was assessed before they worked on the scenarios), reran the analyses while controlling for the effects of the control variables on all other variables (Model 2). We report standardized and unstandardized regression coefficients. The standardized estimates can be interpreted according to Cohen's guidelines (1988) guidelines with values above .10 indicating small effects, values above .30 indicating moderate effects, and values above .50 indicating large effects. All significance testing was performed at the .05 level.

\section{Study 1 Results}

Table 1 shows descriptive information and correlations among all variables. On the RJP task, most participants scored in the 'excellent fit' or 'very good fit' range, with a mean of $28.30(S D=$ 2.59) out of a possible 36 points. In total, $51 / 105$ participants scored in the 'excellent fit' range, 53 participants scored in the 'very good fit' range, and 1 participant scored in the 'quite good fit' range. Scores on the self-efficacy measure had a mean of $4.91(S D=1.41)$. Scores on the interest measure had a mean of $4.14(S D=1.03)$, and scores on the 'match' measure had a mean of $4.67(\mathrm{~S} D=1.28)$.

\section{[Insert Table 1 here]}

Bivariate correlations in Table 1 show a significant association between RJP scores and interest in a teaching career, but not between RJP scores and self-efficacy or attribute match. In Model 1, when estimating all relations without controlling for prior career intentions, we did not obtain a statistically significant effect for self-efficacy (standardized $\beta=-0.078, p>.05$ ). Similarly, scenario scores did not statistically significantly predict the match between own attributes and the attributes required to be a teacher (standardized $\beta=0.058, p>.05$ ). However, scenario scores significantly predicted interest in exploring a teacher career (standardized $\beta=0.256, p<.01$ ).

The findings were robust after including the control variable prior career intentions: In Model 2 with the control variable, the effects for self-efficacy and for the perceived match between own attributes and the attributes required to be a teacher remained not statistically significant (standardized $\beta=-0.113, p>.05$, and standardized $\beta=0.006, p>.05$, respectively). Scenario scores still statistically significantly predicted interest (standardized $\beta=0.205, p<.01$ ). The control variable prior career intentions statistically significantly predicted self-efficacy (standardized $\beta=0.186, p<$ .01 ), match (standardized $\beta=0.276, p<.01$ ), and interest (standardized $\beta=0.269, p<.01$ ), but not scenario scores (standardized $\beta=0.060, p<.05$ ).

\section{Study 1 Brief Discussion}

In Study 1 we found that scores from an RJP intervention were significantly associated with interest in exploring a teaching career, with a small effect size, even after controlling for prior career interests. The results suggest that objective person-vocation fit measured using an RJP intervention is 
related to interest in a teaching career among university students studying STEM-related subjects. To follow up on this finding, we conducted interviews with students who had completed the RJP intervention in order to understand their attitudes towards teaching as a career, other attraction methods, and in particular, their reactions to completing the RJP intervention.

\section{Study 2 Method}

\section{Participants}

Participants who completed the initial online survey were invited to be interviewed for Study 2. Of the original 111 respondents, 39 indicated that they would be willing to be interviewed. From this group of 39, 17 participants were selected based on subject representation and from responses in Study 1 that indicated an openness to a range of career paths (i.e., we did not select participants who indicated strongly fixed career paths in a non-education field). Three participants did not respond to further prompting for interviews. The final sample for Study 2 included 14 students (13 undergraduates; 1 Masters) representing Economics and Finance (5), Physics (3), Engineering (4), Maths (2). The mean age of participants was 22.3 years (55.6\% female).

\section{Procedure}

The participants were invited to an interview to take place via video-conference or telephone, and for which they would be offered an additional $£ 6$ Amazon voucher. The interviewer used a structured interview protocol to conduct the interview. The interviewer opened with an introduction and then posed general questions about participants' academic background and general career choices in order to establish rapport (e.g., "What kind of careers are you considering after your degree?", "How will you make this decision?"). The interview then moved to questions about attraction and recruitment methods:

- Have you considered teaching as a career? (If yes) What triggered your interest? (If no) Why do you think you have not considered it?

- What kinds of information would persuade you to explore teaching?

- You recently completed... (RJPs). Do you remember your results on this activity? What were your thoughts? Did it change your mind about teaching as a career?

\section{Analysis}

Data from the interviews were analysed using a constant comparative approach (Miles \& Huberman, 1994) in which we categorised and compared code segments through the use of a code map built on deductive and inductive code categories. We began with a set of a priori start codes that reflected the key variables from Study 1 (e.g., teaching self-efficacy, interest, person-vocation fit) and collectively developed a set of further codes that emerged through multiple readings of the interview data. The reliability of the coding process was established by having two authors independently reviewing the transcripts and collaboratively discussing the coding decisions. Next, the two coders independently coded sections of the interviews and resolved coding disagreements through discussions until consensus was reached. A code map was used to organise the themes and to identify 
the overarching themes. Due to the multiple relationships between codes and themes, we allowed themes to share codes; that is, a single code could be applied to multiple overarching themes.

\section{Study 2 Results}

A total of 16 codes were identified, subsequently categorised into 3 themes that provide an inductively-derived representation of the codes and the key research questions: Role of Personal Reflection, Critical Influences on Career Decisions, and Patterns of Change. A code map representing the relations between codes and themes can be viewed in Figure 3. The supporting quotes from participants are identified with participant number and gender (e.g., $10 \mathrm{~m}$ is participant 10, male).

\section{Role of Personal Reflection}

Participants in the interviews considered their own personal characteristics and experiences, and weighed their own strengths and weaknesses against the perceived demands of a teaching career. This theme included codes covering diversity of skill-set required, cognitive and non-cognitive attributes, expectations for teaching, interest, fit between personal characteristics and the profession, observation of models, and impact of the intervention.

The impact of the intervention was noted by several of the participants, especially in comparison to other forms of advertising/persuasion, e.g., 'The biggest thing is that it (the RJP activity) stuck in my mind, I've thought about it since... it's not like a conversation that you just forget' (4f). The personal reflection theme included a comparative element, whereby the feedback from practicing teachers brought about an analysis of fit: The activity showed that I had similar ideology as a teacher so made me think that maybe I would be suitable; it really helped me think about how teachers think $(3 \mathrm{~m})$. Not all of the reflections on teaching fit were positive, e.g., I realise that I'm just not patient enough (6m), and The scenarios made me think about the struggles of teaching (4f).

The RJP intervention brought about reflection on personal characteristics perceived to be key for teaching success. One of the key non-cognitive attributes reflected on by participants vis-à-vis the RJP activity was confidence (self-efficacy), especially associated with the feedback provided, e.g., The feedback made me more confident $(10 \mathrm{~m})$, Before this I felt confident that I would have the characteristics and now I feel even more reassured (13f).

\section{Critical Influences on Career Decisions}

This theme captured codes relating to the factors that attracted, and deterred, participants from pursuing a teaching career, including references to the current intervention, advertisements for teaching (e.g., Every lesson shapes a life), career progression, sources of information, observation of models (positive and negative), and personal and social utility. Interviewees reported viewing recruitment advertisements from Teach First and the Department for Education (DfE) on social media (Instagram, Facebook), on television, and on public transport. Views were mixed about the persuasiveness of the advertisements, e.g., They don't really have an impact, $11 \mathrm{~m}$, and I'm sceptical 
as to whether adverts should be used to promote teaching $(11 \mathrm{~m})$. Three of the participants suggested that more explicit information about the career path progression available in a teaching career would be beneficial, e.g., Career progression should be advertised; what is teacher training a stepping stone to? (4f). In terms of personal utility, several of the participants noted that the tax-free grant for training seemed generous and appealing. Influences on career decision-making included parents and especially past teachers, e.g., I had a very inspirational physics teacher who was very passionate about physics and... who clearly enjoyed what he did (3m).

The RJP intervention was noted as a potential source of information for career decisionmaking, I found this quite exciting! Made me think that there are more aspects to school life that make teaching more fun (8f), although not all agreed: I thought the scenarios were an oversimplification of the role, and not particularly influential (5f), and You should show candidates what they gain from teaching. If the scenarios included success stories it might be more motivating $(1 \mathrm{~m})$.

\section{Patterns of Change}

In this theme, participants noted how their thinking about pursuing teaching as a career has changed, due to a range of experiences and activities, including the RJP intervention. Codes in this theme included, role clarity based on experiences, observation of models, attitude change, fit with the profession, interest, and impact of the intervention. In terms of change associated with the intervention, several participants noted changes in the way of viewing the profession after the RJP, for example, Actually after this activity I looked up more information. I feel my career interests have broadened after this survey (8f), and It (the RJP) has made me think about it more (13f), and It did make me feel more positive about a career in teaching. It is not a closed door $(2 \mathrm{~m})$. The authenticity of the intervention was noted by several participants, It felt like having a go at being a teacher (13f), although not all were unequivocally positive about a potential career: (After completing the RJP activity) I thought 'oh this is something I could do, perhaps it's not all that bad' (7f).

In general, patterns of change were influenced by past models, especially successful teachers (parents, influential teachers), from experiences such as mentoring or volunteering in school-related experiences, and less so by recollections of advertisements published by DfE and Teach First.

Participants rated the RJP activity as an intervention that was authentic, valued, and generally a positive influence that in some cases evoked consideration of change in career intentions.

\section{Study 2 Brief Discussion}

The results from Study 2 showed three themes derived from the 16 codes applied to the interview data. Participants were generally positive about the impact of the RJP intervention, and noted its influence on fostering personal reflection, career decision-making, and change related to their career choices. Of particular interest were the reports that the RJP increased interest in the profession and activated behavioural changes (I looked up more information [about teaching]) in contrast to the general consensus that social media campaigns (for example from DfE) had modest impact on career decision-making. 


\section{General Discussion}

Perceived fit is one of the strongest predictors of attraction to a job or vocation (Uggerslev et al., 2012), yet recruitment strategies and methods using a person-vocation fit approach have rarely been used in education. The two studies in this article provide insight into possible new approaches to attract and recruit applicants into teacher education by providing exposure to realistic teaching situations and by delivering detailed and tailored fit messages about applicants' fit to teaching. Building on research from organisational psychology and grounded in robust theory, realistic job previews (RJPs) have the potential for use as a tool in the teacher attraction and recruitment process.

We posed two primary research questions, the first about the relations between scores in an RJP intervention and self-efficacy, career interest, and attribute match, and the second about the internal and external influences on career decision-making for university students in STEM-related disciplines. We found that scores on a brief (15-20) minute intervention were associated with career interest, even after controlling for prior interest in teaching, but not teaching self-efficacy or perceptions of attribute match. We also found that potential applicants were aware of, but generally unpersuaded by, current advertisements designed to promote teaching as a career. Most of the participants in the Study 2 interviews reported a certain flexibility to their career plans, and noted that the RJPs had the potential to change the ways that they viewed the teaching profession. Changes in career intentions were also influenced by influential examples and models, especially previous teachers and in some cases, parents. Short-term changes were associated with the RJP intervention, although further work is needed to understand the robustness of these changes.

\section{Subjective and Objective Person-Vocation Fit}

The fit between a potential applicant and a teaching career is influenced by beliefs about the personal and social utility of teaching, but also about the perception of fit with the attributes required for success in the profession. Self-assessment of this fit might be gained through relevant experiences, for example, through getting feedback from volunteering in a school, or from delivering informal teaching in a community club. However, subjective person-vocation fit may be inaccurate due to insufficient information; beliefs about potential teaching competence may be mis-guided if relevant experiences are limited or if messages from important others are either not forthcoming or are not convincing. The scenarios in RJPs deliver a believable snapshot of the workplace that can enhance the impact of recruitment messaging, but they can also be developed, as is the case in the intervention in this article, to provide relatively 'objective' feedback about fit. The alignment with experienced teachers is the kind of objective feedback that is valuable but rarely experienced in the recruitment phase. Although the results in Study 1 did not show a significant link between the RJP and teaching self-efficacy or attribute match, they indicate that higher RJPs can spark participants' interest in exploring teaching as a career.

\section{How 'Realistic' Should Realistic Job Previews Be?}

One problem with a recruitment strategy built on the promotion of social utility (e.g., the 
DfE's Every lesson shapes a life campaign), is that some teacher trainees will hold unrealistic expectations when the inevitable challenges of teaching crop up, resulting in high levels of attrition in training and at the early career stage. In order to reduce attrition, potential applicants considering entering the teaching profession should consider the rewards and the typical challenges to be faced in the career. Realistic job previews are designed, by definition, to be authentic, and in order to be believable, RJPs should not offer an unqualified positive portrayal of the day-to-day challenges faced by teachers. We know from previous research that negative information lowers applicant attraction to an organisation (Bretz \& Judge, 1998); however, the right balance between realism and positive/negative content to maximise authenticity is not known. Further work is clearly needed to test the impact of message valence on both recruitment success and on retention rates post-recruitment.

\section{Future Directions}

Implications for practice. Online RJPs provide a cost-effective and highly scalable approach to deliver a research-supported recruitment intervention. Providing tailored real-time feedback to potential applicants enhances organisational attractiveness (Hu et al., 2007). Recruitment strategies can be designed to feature multiple messages, with a person-vocation fit message delivered alongside messages centred around the personal and social utility of a teaching career. Recruitment websites could feature RJPs with personally tailored feedback designed to offer potential applicants a taste of the classroom, and preliminary feedback on the fit between their judgment and that of experienced professionals. However, the likelihood of STEM students accessing a teacher recruitment website may be low without incentives. One alternative might be to directly send recruitment messages to students in shortage subjects through university career advisory services, possibly with low-value financial incentives (for example, shopping voucher) provided for completion of the RJP. Such an approach, although incorporating some costs, would likely be far less expensive than the estimated $£ 400$-per-recruit spent on current advertising (Carr, 2020).

Implications for research. More research is needed to understand how recruitment messages differentially influence decision-making of university students. Our results from Study 2 suggest that most interviewees were sceptical about the effectiveness of current recruitment advertising in the UK. A more rigorous test of the effectiveness of advertising messages would be useful, especially using a longitudinal design that measured not only interest in entering a training program (the anticipated outcome of personal and social utility messages), but also retention in the early years of the profession. It is possible that an RJP intervention will not increase the total number of applicants applying for ITE, but the hypothesis should be tested that RJPs increase the number of good applicants who are more likely to stay in the profession due to realistic expectations about career challenges and rewards. For example, some evidence of self-selection out of a teaching career was seen in the comments from participants in Study 2, e.g., I realise that I'm not patient enough $(6 \mathrm{~m})$ and The scenarios made me think about the struggles of teaching (4f). Research that evaluates in close detail the longer-term impact of specific recruitment efforts would be highly valued, building a better 
understanding of how specific messages and strategies influence recruitment and longer-term retention.

\section{Strengths and Limitations}

The study provides one of the first systematic studies of how a research- and theory-based recruitment intervention could influence potential applicants' interest in the profession. Our study represents a starting point in teacher recruitment research, with considerable more work needed before firm conclusions can be drawn. There are several limitations which should be heeded in subsequent studies. The current study relies on a volunteer sample which may not represent students in STEMrelated subjects generally, with no representation from large-enrolment STEM subjects such as Biology and Chemistry. Future iterations of RJP interventions for teacher recruitment purposes could manipulate the fit message to test which elements of the intervention (scenarios, fit message, feedback from experienced teachers) have an effect on career interest. We did not find an effect on self-efficacy and it may be that a longer, more intense, RJP intervention offering more opportunities for vicarious experience and verbal persuasion (Bandura, 1997) is required to influence these self-beliefs. The Study 2 qualitative research drew from a limited sample, and although the insights derived from this sample were valuable in providing explanation of Study 1 findings, a deeper dive (with a larger sample) into how potential teacher applicants respond to current and potential recruitment efforts would provide valuable insights for future recruitment efforts.

\section{Conclusions}

This article contributes to our knowledge of teacher attraction and recruitment methods, with the finding that a brief, scalable, online RJP intervention was associated with interest in a teaching career. The findings provide some insight into the potential role that person-vocation fit might play in teacher attraction and recruitment strategies in the future. In a time of teacher shortages, the article also highlights the need to study the effectiveness of current recruitment policies, and how relevant theory and research can contribute to improving the effectiveness of recruitment policies and methods. 


\section{References}

Author et al., 2020a.

Author et al., 2020b.

Bandura, A. (1997). Self-efficacy: The exercise of control. New York: Freeman.

Barrick, M. R., \& Parks-Leduc, L. (2019). Selection for fit. Annual Review of Organizational Psychology and Organizational Behavior, 6,13.1-13.23.

Baur, J. E., Buckley, M. R., Bagdasarov, Z., \& Dharmasiri, A. S. (2014). A historical approach to realistic job previews: An exploration into their origins, evolution, and recommendations for the future. Journal of Management History, 20, 200-223.

Bergman, M. E., Drasgow, F., Donovan, M. A., Henning, J. B., \& Juraska, S. E. (2006). Scoring situational judgment tests: Once you get the data, your troubles begin. International Journal of Selection and Assessment, 14, 223-235.

Bretz, R. D., \& Judge, T. A. (1998). Realistic job previews: A test of the adverse self-selection hypothesis. Journal of Applied Psychology, 83, 330-337.

Carr, J. (2020). Is the DfE's teaching ad spend paying off? Schools Week. Retrieved from https://schoolsweek.co.uk/is-the-dfes-teaching-ad-spend-paying-off/

Chang, A., Shen, C., \& Judge, T. A. (2016). Development of a multidimensional instrument of person-environment fit: The perceived person-environment fit scale (PPEFS). Applied Psychology: An International Review, 65, 66-98.

De Cooman, R., De Gieter, S., Pepermans, R., Hermans, S., Du Bois, C., Caers, R., \& Jegers, M. (2009). Person-organization fit: Testing socialization and attraction-selection-attrition hypotheses. Journal of Vocational Behavior, 74(1), 102-107.

Department for Education (2019). Teacher recruitment and retention strategy. Retrieved from https://assets.publishing.service.gov.uk/government/uploads/system/uploads/attachment_data/file/ 786856/DFE Teacher Retention Strategy Report.pdf

Earnest, D. R., Allen, D. G., \& Landis, R. S (2011). Mechanisms linking realistic job previews with turnover: A meta-analytic path analysis. Personnel Psychology 64, 865-897.

Fullard, J. (2020). Teacher supply and Covid-19. Education Policy Institute. Retrieved from https://epi.org.uk/publications-and-research/teacher-supply-and-covid-19/

Hackett, R. D., Lapierre, L. M., \& Hausdorf, P. A. (2001). Understanding the links between work commitment constructs. Journal of Vocational Behavior, 58, 392-413

Miles, M. B., \& Huberman, A. M. (1994). Qualitative data analysis: An expanded sourcebook (2nd ed.). Thousand Oaks, CA: Sage.

Patterson, F., Knight, A., Dowell, J., Nicholson, S., Cousans, F., \& Cleland, J. (2016). How effective are selection methods in medical education? A systematic review. Medical Education, 50, 36-60.

Player, D., Youngs, P., Perrone, F., \& Grogan, E. (2017). How principal leadership and person-job fit are associated with teacher mobility and attrition. Teaching and Teacher Education, 67, 330-339. 
Roberson, Q. M., Collins, C. J., \& Oreg, S. (2005). The effects of recruitment message specificity on applicant attraction to organizations. Journal of Business and Psychology, 19, 319-339.

See, B. H., \& Gorard, S. (2019). Why don't we have enough teachers? A reconsideration of the available evidence. Research Papers in Education, DOI: 10.1080/02671522.2019.1568535

See, B. H., Morris, R., Gorard, S., \& El Soufi, N. (2020). What works in attracting and retaining teachers in challenging schools and areas? Oxford Review of Education, DOI: 10.1080/03054985.2020.1775566.

Tschannen-Moran, M., \& Woolfolk Hoy, A. (2001). Teacher efficacy: Capturing an elusive construct. Teaching and Teacher Education, 17, 783-805.

Uggerslev, K. L., Fassina, N. E., \& Kraichy, D. (2012). Recruiting through the stages: A metaanalytic test of predictors of applicant attraction at different stages of the recruiting process. Personnel Psychology, 65, 597-660.

UNESCO (2016). The world needs almost 69 million new teachers to reach the 2030 education goals. Retrieved from https://unesdoc.unesco.org/ark:/48223/pf0000246124

Watt, H. M., \& Richardson, P. W. (2007). Motivational factors influencing teaching as a career choice: Development and validation of the FIT-Choice scale. The Journal of Experimental Education, 75(3), 167-202.

\section{Table 1}

Descriptive Statistics, and Bivariate Correlations Among All Variables

\begin{tabular}{lccccc}
\hline Variable & 1. & 2. & 3. & 4. & 5. \\
\hline 1. Scenario Scores & - & .078 & $\mathbf{. 2 5 6}$ & .058 & .107 \\
2. Self-efficacy & & - & $\mathbf{. 1 8 5}$ & $\mathbf{. 5 3 8}$ & $\mathbf{. 3 1 6}$ \\
3. Interest & & & - & $\mathbf{. 2 9 2}$ & $\mathbf{. 4 9 7}$ \\
4. Attribute Match & & & & - & $\mathbf{. 4 8 7}$ \\
5. Prior Career Intentions & & & & & - \\
\hline$M$ & 28.324 & 4.925 & 4.135 & 4.667 & 2.694 \\
$S D$ & 2.552 & 1.398 & 1.032 & 1.284 & 1.772 \\
\hline
\end{tabular}

Note. Statistically significant correlations at $p<.05$ are boldface. Scenario Scores refers to score on the RJP task. 
Table 2

Results from the Regression Model Predicting Self-efficacy, Interest in Teaching, and Match Between Own Skills and Skills Required to be a Good Teacher with Scores on the Scenario-based Task, without (Model 1) and with (Model 2) Controlling for Prior Career Intentions to Explore Teaching as a Career Assessed Before Working on the Scenario-based Task

\begin{tabular}{|c|c|c|c|}
\hline Predictor & Outcome & Est. (SE) & Std. \\
\hline \multicolumn{4}{|c|}{ Model 1} \\
\hline Scenario Scores & Self-efficacy & $-0.043(0.054)$ & -0.078 \\
\hline Scenario Scores & Interest & $0.103(0.037)$ & 0.256 \\
\hline Scenario Scores & Attribute Match & $0.029(0.156)$ & 0.058 \\
\hline \multicolumn{4}{|c|}{ Model 2} \\
\hline Scenario Scores & Self-efficacy & $-0.062(0.053)$ & -0.113 \\
\hline Scenario Scores & Interest & $0.083(0.031)$ & 0.205 \\
\hline Scenario Scores & Attribute Match & $0.003(0.042)$ & 0.006 \\
\hline Prior Career Intentions & Self-efficacy & $0.259(0.069)$ & 0.328 \\
\hline Prior Career Intentions & Interest & $0.276(0.048)$ & 0.475 \\
\hline Prior Career Intentions & Attribute Match & $0.353(0.058)$ & 0.487 \\
\hline Prior Career Intentions & Scenario Scores & $0.153(0.135)$ & 0.107 \\
\hline
\end{tabular}

Note. Est. $=$ Unstandardized Parameter Estimate; S.E. $=$ Standard Error of the Estimate; Std. $=$ Standardized Parameter Estimate; Statistically Significant Results at $\alpha=.05$ are in Boldface. 
Figure 1

Example of Realistic Job Preview Scenario: Mark Plays with Mobile Phone During Class

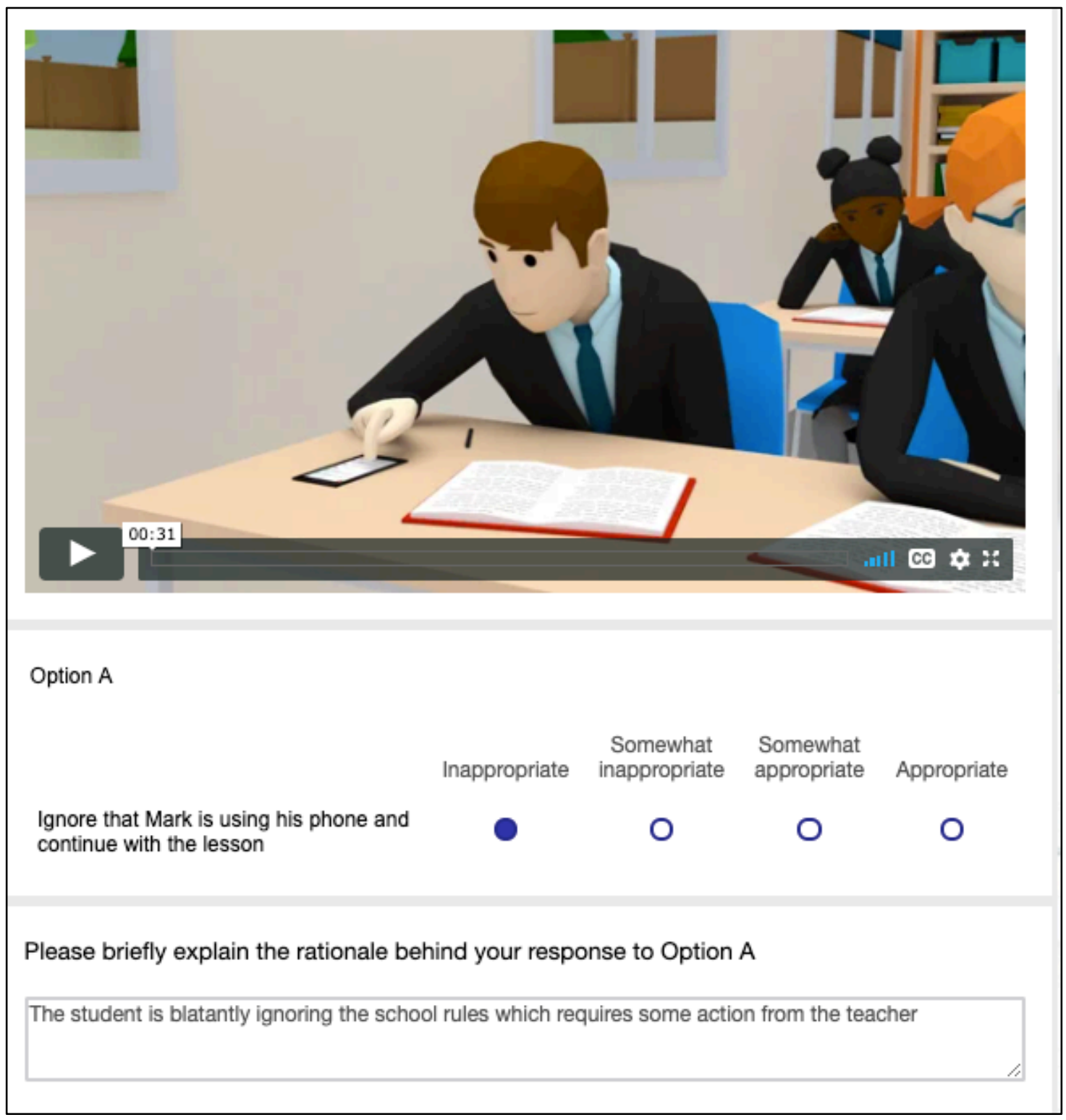




\section{Figure 2}

Example of Realistic Job Preview Feedback

\section{Question 1 Feedback}

This section allows you to view how most experienced teachers rated question 1. You can use the feedback from experienced teachers to reflect on your own responses to the question.

Q1. One of your Year 8 English pupils, Mark, has been playing with his mobile phone throughout the lesson. The school has a no-phone policy. You have asked Mark for his phone, which has angered Mark.

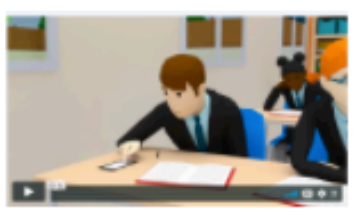

\section{Option A}

Somewhat Somewhat Inappropriate inappropriate appropriate Appropriate

Ignore that Mark is using his phone and continue with the lesson

You thought Option A was Inapproprlate.

Your rationale: The student is blatantly ignoring the school rules which requires some action from the teacher

Experienced teachers agree! As you suggest this would be an inappropriate response to this situation.

You cannot ignore a behaviour that exists in the school behaviour policy. You need to let Mark know that you have noticed him using his phone either by verbal or non-verbal communication, and issue an appropriate consequence in line with the school's behaviour management policy. 


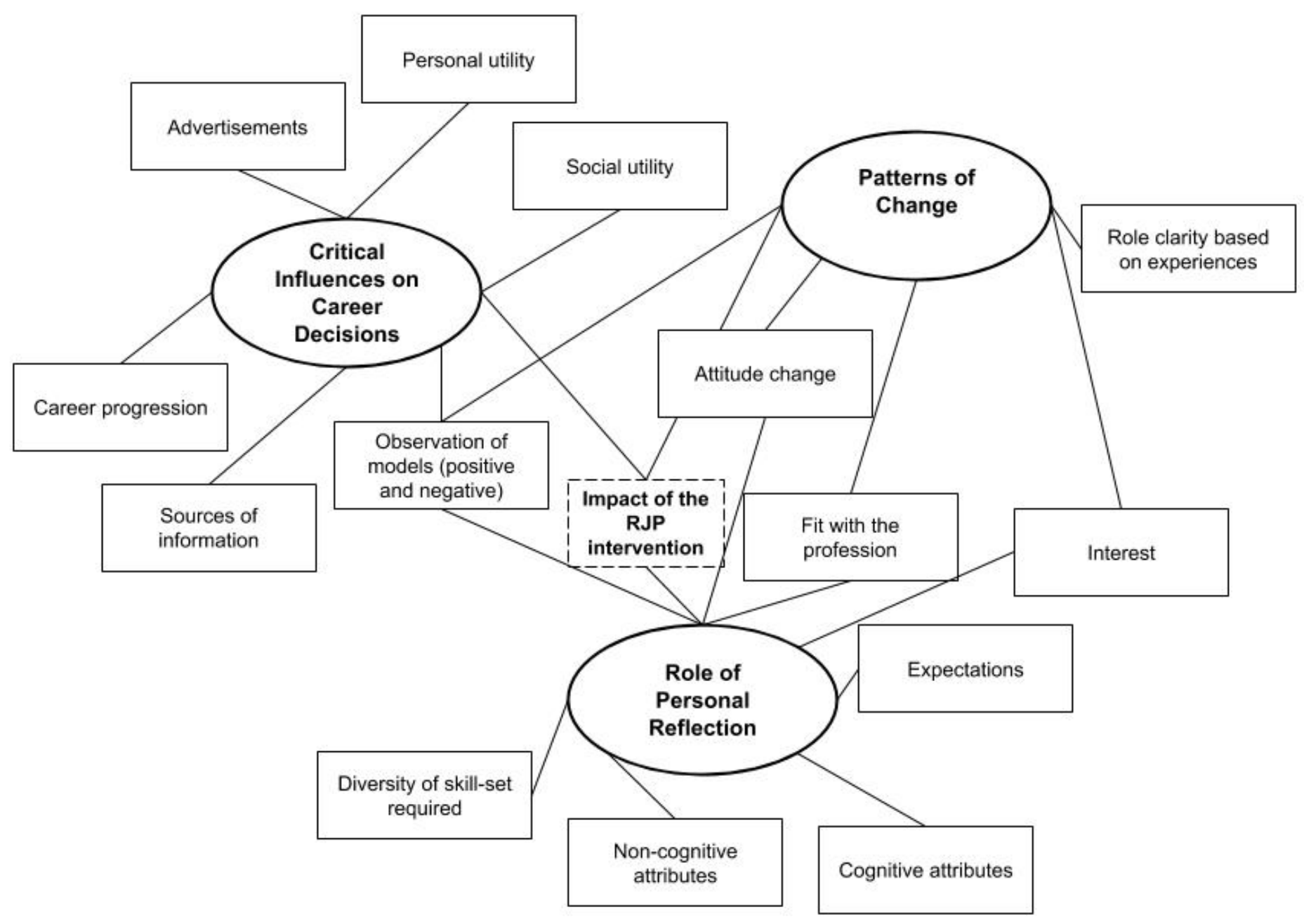

Figure 3

Map of Relationships Between Codes and Themes 